Мария Полякова

ORCID: 000O-0003-3580-9718

Российский новый университет

Москва, Россия

\title{
ПРОПОВЕДИ ЛЮТЕРА КАК СПОСОБ ТРАНСЛЯЦИИ ЕГО ОБРАЗОВАТЕЛЬНОЙ ПРОГРАММЫ
}

\author{
https://doi.org/10.34739/clit.2020.14.03
}

\section{MARTIN LUTHER'S SERMONS AS A WAY OF BROADCASTING HIS EDUCATIONAL PROGRAM}

\begin{abstract}
The article considers some aspects of the genesis of preaching as a special genre of oral creativity in the Christian tradition and its importance in the Protestant propaganda of the confessional period. According to the author, preaching was of paramount importance to Luther starting with the first steps of his revision of the Christian creed. The reformer used the sermon not only as an instruction in the faith, but also as a kind of translator of his educational program - because only through the training of the population could he, from his point of view, convey the faithful the "divine message" and the idea of salvation.

Keywords: Martin Luther, Reformation, sermon, postilla, catechism
\end{abstract}

\section{Проповедь как жанр устного творчества}

На сегодняшний момент понимание слова «проповедь» очень широко и многозначно, поэтому трудно дать ему однозначную интерпретацию. По наиболее распространенному в христианской среде определению, проповедь - это речь религиозного характера, произносимая священнослужителем в церкви, и имеющая своей задачей поведать и разъяснить слушающим учение Иисуса Христа ${ }^{1}$. Но такое толкование не охватывает всех форм проповеди, исторически и географически сложившихся в социальной и лингвистической культуре человечества. К примеру, подобная трактовка не учитывает многообразные типы поучений, которые

${ }^{1}$ Словарь русского языка, Москва 1999. 
сформировались и успешно использовались в дохристианский период, получив в дальнейшем свое развитие в иных религиях и учениях. Также представленное определение не включает в себя те виды наставлений, которые передавались в формах, отличных от устной речи.

Толковый словарь русского языка предлагает более широкую трактовку проповеди, различая «...речь религиозно поучительного характера, произносимую священнослужителем в церкви» и «...распространение, пропагандирование каких-либо взглядов, идей и т. п.»². Обращает на себя внимание переносное значение слова - 'наставление, нравоучение', составившее основу особого литературного жанра - сочинения, заключающего в себе наставление, поучение. Совершенно очевидно, что представленные толкования не исчерпывают богатый потенциал термина «проповедь», но, по крайней мере, демонстрируют варианты его использования в коммуникативной практике.

Кроме проповеди в христианской литературной традиции выделяют ее разновидность - постиллу как простейшую форму «...проповеди, в католической церкви, состоящей из объяснения только что прочитанных слов Евангелия или апостола, то есть отрывков из Деяний и Посланий апостолов»3. Постилла начинает играть важную роль в пропаганде конфессиональной эпохи, что, по всей видимости, связано с просветительским характером лютеровской реформы церкви.

В этой связи показательна история возникновения проповеди как особого жанра христианской нравоучительной литературы (и собственно термина), точнее ее генезис на заре распространения христианства. С точки зрения этимологии, «проповедь» (в ее старославянском варианте) вероятней всего

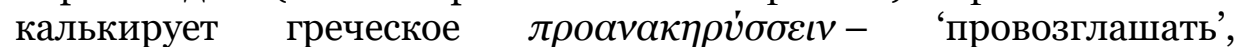
'провозвещать'. Влияние греческого языка (точнее - койне́ (коıvі) 4 ) на лингводидактическую традицию раннего христианства очевидно и вполне объяснимо. К примеру, практически все раннехристианские проповедники, как и апостолы Христа, носили греческие имена (вкупе с иудейскими), и на греческом языке говорили в синагогах по всему восточному Средиземноморью. Вернер Йегер упоминает множество языковых форм,

\footnotetext{
2 Толковый словарь русского языка, Москва 1935-1940.

3 А. Чудинов, Словарь иностраннъх слов, вошедиих в состав русского языка, Санкт-Петербург 1910.

4 Язык повседневного общения носителей родственных языков или диалектов, возникший на основе наиболее распространённого из них и вобравший черты других языков или диалектов (См.: Т. Ефремова, Толковый словарь, Москва 20оо).
} 
унаследованных из греческого языка и установившихся в практике раннего христианства; многие из них хорошо известны и понятны

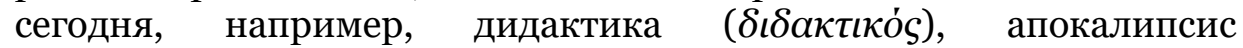

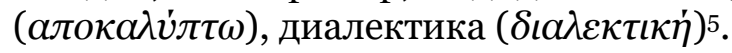

При этом диалектика явно сродни такому понятию как диатриба ( $\delta \iota \alpha \rho \iota \beta \eta)$. Будучи особым жанром античной литературы, диатриба развилась из сократической беседы, активно использовалась киниками, стоиками и эпикурейцами в их публичных философских выступлениях, а ее форма собственно и послужила основой для христианской проповеди.

Диатриба и, позднее, проповедь складываются как жанры устного творчества, ведь и адресованы они были, прежде всего, широкой аудитории, и содержали в себе набор определенных средств и приемов, которые были направлены именно на убеждение. Показательным образчиком уже христианских диатриб можно считать Послания апостола Павла, обращавшего язычников. В устной форме протекала и раннехристианская катехизация ${ }^{6}$, которая долгое время являлась единственным видом преподавания основ веры и распространялась не только на детей, но и на взрослое население. Именно из этих потребностей вырастает и «катехизис» как «...лаконичная, но систематически изложенная сумма вероучения...», способная «...в простой и доступной форме изложить перед язычниками основы христианской веры»7.

Причем, первоначально в роли катехизисов выступали все те же Послания... и другие произведения патристического периода, в том числе Учение двенадцати апостолов (Дидахе́), где впервые обращено внимание на таинства крещения и евхаристии.

Следует также отметить, что в дохристианский период связь проповедования, наряду с пророчеством, с учительским делом считалась неоспоримой. Ярким подтверждением этой мысли является фигура ветхозаветного Экклезиаста, объединяющего

5 В. Йегер, Раннее христианство и греческая пайдейя, пер. с англ. и вступит. стат. О. Алиевой, Москва 2014, с. 30-31.

${ }^{6}$ В апостольские времена «катехизация» означала устное наставление во всем, что имело отношение к основам христианской веры и жизни; впоследствии это понятие стало употребляться в более узком смысле, как подготовка к принятию таинства крещения и приобщению к жизни в христианской общине. (М. Корзо, Украинская u белорусская катехетическая традиция конца XVI-XVIII вв.: становление, эволюция и проблема заимствований, Москва 2007, с. 3).

${ }_{7}$ М. Корзо, Украинская и белорусская катехетическая традиция конца XVI-XVIII вв.: становление, эволюция и проблема заимствований, Москва 2007, с. 3. 
в себе образы мудреца, проповедника (мудрости) и, тем самым, учителя (наставника) все той же мудрости ${ }^{8}$.

Таким образом, просветительский и педагогический потенциал проповеди (а также диатрибы, беседы или наставления) проявился практически в момент ее оформления в специфический тип вербальной коммуникации и своего рода практики взаимоотношений обучающегося (внимающего) и обучающего (наставляющего). Однако особое значение проповедование и тесно связанная с ним катехизация приобретают в эпоху Реформации.

\section{Роль проповеди в протестантской пропаганде. Мартин Лютер}

Начавшаяся с весьма «невинного» выступления августинского монаха (Мартина Лютера) 31 октября 1517 г. Реформация, быстро хватила всю Европу и привела к изменениям не только в религиозной и инстиуционально-церковной жизни западного общества, но и к пересмотру всего корпуса прав человека. Вывод Лютера о спасении через безграничную веру в божественную благодать привел к тому, что человек становился ответственным за свою судьбу. Однако распознать божественный замысел в отношении себя можно было только через выраженное в Священном Писании послание, а также через собственную праведную жизнь, что, в свою очередь, поставило перед реформаторами ряд задач: сделать Слово Божье доступным, научить верующих услышать его (через проповедь), увидеть его (через чтение), а также соблюдать Божьи законы и установления. Уже с первых шагов лютеровские реформы были направлены на претворение в жизнь этого грандиозного плана. Примечательно, что подготовка Лютером перевода Библии, активное проповедование и толкование отдельных частей Священного Писания, а также его редукция до краткого изложения (собственно создание катехизиса) шли параллельно, тесно взаимосвязаны и служили общей цели религиозного просвещения населения.

Многие исследователи Реформации и протестантизма отмечают их преимущественно проповеднический характер. К примеру, итальянский исследователь Фульвио Феррарио называет деятельность Лютера «практической теологией», что как нельзя

8 Учитель и ученик: становление интерсубъектнъх отношений в истории педагогики Востока и Запада (цивилизации Древности и Средневековъя), ред. Н. Баранникова и В. Безрогов, Москва 2013, с. 153. 
лучше отражает суть изменений, которые происходят в ту эпоху9. Сам реформатор, предприимчивый и деятельный, большое значение придавал проповеди и именно в ходе проповедования «оттачивал» свои теологические и педагогические навыки, что позволило ему в дальнейшем выработать действительно лаконичную и доступную версию катехизиса, который, в этой связи, можно рассматривать как своего рода сумму, итог религиозного и проповеднического опыта, накопленного Лютером в предыдущие годы.

Проповедование и катехизация тесно связаны друг с другом, так как представляют собой «...систематизированную экспозицию истории спасения».

Несомненным подспорьем в деятельности немецких реформаторов оказалась возможность, благодаря книгопечатанию, преобразования устной проповеди и наставления в печатное слово, в книгу, которая стала также одним из первых учебников в современном понимании этого слова, доступным широким слоям населения. Несмотря на то, что культура XVI в. оставалась еще преимущественно устной, сам факт тиражирования и массового распространения произведений реформаторов нельзя недоценивать.

Роль печатного слова в деле Лютера подтверждается многочисленными изданиями его произведений, начавшимися c первых дней Реформации. Практически все его проповеди, разъяснения им десяти заповедей, молитвенники с комментариями записывались его учениками и издавались. В оцифрованной коллекции Баварской государственной библиотеки в Мюнхене ${ }^{10}$ содержится более тысячи работ реформатора, изданных только в период с 1518 по 1600 гг., и подавляющее большинство их составляют проповеди, комментарии к отдельным разделам Библии, толкования десяти заповедей, правила и рекомендации по совершению таинства крещения, катехизисы (на немецком и латинском языках).

Задолго до написания своего катехизиса Лютер проповедовал (в основном в форме постилл) отдельные его части: разъяснял суть десяти заповедей, Символа веры и Господней молитвы («Отче наш») и тем самым уже в 1517-1518 гг. «...предсказал метод, который в дальнейшем собирался использовать» ${ }^{11}$. Явно для практической деятельности верующих он составил сборник основных молитв (1522) и руководство по

\footnotetext{
9 M. Lutero, Il Piccolo Catechismo, a cura di F. Ferrario, Torino 2004 (Introduzione), p. 6. ${ }^{10}$ Digitale Bibliothek - Münchener Digitalisierungszentrum.

${ }^{11}$ P. Колб, Небольшая, но замечательная книга, www.ihtik.lib.ru/2013.05_ihtik_relig/, [дата доступа: 10.12.2019].
} 
проведению обряда крещения (1523). Как отмечалось, все эти произведения претерпели ряд переизданий под разными названиями: «книжка с молитвами» (Betbüchlin), «настольная книга» (handbuch), «книга для чтения» (leßbüchlin), «инструкция» (vnterrichtung), «руководство» (anlaitung), «наставление» (unterwaysung), «разъяснение» (erklerung) ${ }^{12}$ и др., что свидетельствует об их популярности в немецком обществе.

Тем самым можно видеть, что для Лютера и его последователей проповедь являлась способом разъяснения и распространения нового вероучения, по сути дела, она исполняла те же функции, что и ранняя христианская проповедь.

\section{Проповедъ о том, что нужно посъиять детей в иколу}

Решающим событием в развитии как просветительской деятельности реформаторов (включая массовое открытие школ), так и проповеднического искусства (а также его теоретического осмысления) стала печально известная визитация саксонских приходов 1527 г. (кроме Лютера в ней участвовали его ближайшие друзья и соратники - Филипп Меланхтон и Иоганн Бугенхаген), которая выявила крайне плачевное состояние дел в области христианского образования прихожан. В своем Предисловии к Краткому катехизису Лютер отмечал, что простые люди «...даже понятия никакого не имеют о христианском учении»13, а также «...многие пасторы совершенно неспособны и не готовы учить» 14. Далее он призвал пасторов и проповедников «...от всего сердца посвятить себя служению, иметь сострадание к людям и помогать нам [реформаторам] в насаждении сего Катехизиса среди людей, особенно среди молодежи» 15.

Однако эта визитация имела далеко идущие последствия. Практически сразу после нее появляется так называемое «Наставление визитаторов...»16. Меланхтона, где, кроме разъяснения

\footnotetext{
12 Немецкие термины даны в графике автора или издателей XVI в.

13 М. Лютер, Краткий катехизис, Минск 1996, с. 4

14 Ibidem.

15 Ibidem.

16 Полное название произведения: Unterricht der Visitatorn an die Pfarrhern im Kurfürstenthum zu Sachssen 'Наставление визитаторов настоятелям приходов в Курфюршестве Саксонском'. У Ю. Голубкина «Наставление визитаторов, предназначенное для пасторов в землях герцога Генриха Саксонского», что ближе всего оригиналу, но в русскоязычой традиции, как правило, используется термин «Саксонский (учебный) план», хотя в действительности речь в этом сочинении идет о том, что должны знать и уметь делать священники в том или ином приходе
} 
основ христианской веры (в лютеровско-реформатском понимании), подробно изложены ключевые принципы организации латинских школ. Следует ряд школьных уставов (в составе церковных), устанавливающих определенные нормы регуляции обучения в таких школах, а также в так называемых немецких школах, где преподавание велось на немецком языке. Автором одного из первых уставов - Брауншвейгского, стал один из участников визитации, Бугенхаген ${ }^{17}$.

Кроме организационной деятельности визитаторы снабдили пасторов и учителей своеобразным методическим пособием по основам христианской веры - катехизисом, точнее двумя. Их автором стал сам Лютер.

Два варианта лютеровского катехизиса появились в 1529 г. Это Краткий катехизис (Enchiridion) для детей и слуг, которых должны были обучать, прежде всего, родители и хозяева, и Болъшой катехизис для пасторов и других учителей (тех же родителей и хозяев), явившийся, таким образом, своего рода методическим пособием для людей, наставляющих в христианском учении. Большой катехизис снабжен двумя предисловиями автора, первое из которых предназначено для тех, кто должен его проповедовать (пасторов и учителей), второе (краткое - в русском переводе) - для детей и простых людей (прислуги). Это предисловие представляет вариант проповеди, которую пасторы или другие учителя произносили для подобной категории граждан, так как читать последние должны были именно Краткий катехизис, специально для них составленный.

Первое издание собственно Краткого катехизиса было осуществлено в форме таблиц (плакатов), первые три из которых вышли в январе 1529 г., а остальные - в середине марта того же года вместе с опубликованными раньше (в январе). Эти таблицы можно было развешивать на стенах церкви и школы с целями обучения, а также изучать в кругу семьи. В мае 1529 г. в Виттенберге Краткий катехизис был опубликован в виде брошюры со Скрижалью. Издание было дополнено предисловием автора и иллюстрациями. Кроме того, незадолго до этого он появился в Гамбурге на нижненемецком языке, что говорит о важности подобного издания для всех немецких земель.

(См.: Ph. Melanchton, Unterricht der Visitatorn an die Pfarrherrn im Kurfürstenthum zu Sachssen, Nürnberg 1528).

${ }_{17}$ См.: 3. Лурье, М. Полякова, Брауншвейгский церковный устав Иоганна Бугенхагена о реборме образования, «Proslogion: проблемы социальной истории и культуры средних веков и раннего нового времени» 2018, № 2(4), с. 189-216. 
Уже в августе-сентябре того же года катехизис вышел на латинском языке. В 1531 г. Лютер внес последние исправления в текст касательно исповедования, и в таком виде Краткий катехизис вошел в Книгу согласия Евангелическо-Аугсбургской Церкви 1580 г. ${ }^{18}$.

Окончательно итоги известного инспектирования были подведены Лютером в «Проповеди о том, что надо посылать детей в школу» (Eine Predigt das man kinder zur Schulen halten solle, 1530) произведении, в котором постоянно прослеживается беспокойство реформатора за начатые им реформы и где он призывает родителей - c одной стороны и городские власти - c другой проявить понимание к образованию подрастающего поколения, не упустить его воспитания:

...ныне и власть также должна заставлять подданных посылать своих детей в школу. (...) Она поистине обязана сохранять вышеупомянутые служения и сословия, чтобы остались священники, юристы, писари, врачи, учителя и все другие, без кого невозможно обойтись. Если [власти] могут принуждать подданных, способных носить пики и ружья, взбираться на стены или делать что-либо другое, необходимое для ведения войны, то гораздо более того они могут и должны заставлять подданных посылать детей учиться в школы; потому что здесь стоит гораздо более ожесточенная война - со злостным дьяволом, имеющим тайный умысел высасывать из городов и княжеств способные личности... ${ }^{19}$.

В проповеди показано разнообразие ремесел/профессий Германии конфессионального периода и важность профессионального образования. Исходя из того, что власти «...должны иметь канцлеров, писцов, советников, юристов и ученых» ${ }^{20}$, Лютер призывал родителей (прежде всего, бюргеров) отдавать детей в школу и воспитывать у ребенка желание к учебе:

Если у тебя есть ребенок, который годится к обучению, и ты можешь его заставить учиться, но не делаешь этого, а также не задумываешься о том, что станется с государством вместе с правом

18 Подробнее о лютеровском катехизисе см.: Формирование картины мира в катехизисах Мартина Лютера, [в:] Школьные пособия раннего нового времени: от Часослова к Orbis sensualium pictus, ред. К. Левинсон, Ю. Куровская, В. Безрогов, Москва 2017, с. 114-137.

19 М. Лютер, Проповедь о том, что нужно посълать детей в школу, пер. О. Курило, [в:] Мартин Лютер - реформатор, проповедник, Москва 1996, с. 118-154, с. 151-152. ${ }^{20}$ Ibidem, c. 139. 
и миром, то ты выступаешь против светской власти, как турок, даже как сам дьявол ${ }^{21}$.

Проповедническому сословию в сочинении уделено особое внимание: «Нет ведь более сокровенных, более благородных дел на земле и в этой жизни, которые могли бы сравниться с праведными и верными обязанностями священника и проповедника» ${ }^{22}$. Кроме того, Лютер призывает родителей отдавать детей на обучение именно этому искусству:

...общине и особенно такому городу (Нюрнбергу) нужны не только купцы или люди, умеющие считать и читать немецкие книги. Немецкие книги сделаны главным образом для простого человека, чтобы он их читал дома. Однако для чтения проповедей, для управления и вершения правосудия как в духовной, так и в светской сфере определенно недостаточно всех наук и языков мира, особенно в наше время, когда общаешься больше с другими людьми, нежели с соседом Гансом ${ }^{23}$.

Упоминание в данном случае Нюрнберга объясняется тем, что условия жизни в нем позволяли расширить спектр преподаваемых дисциплин: именно там Меланхтоном в 1526 г. была открыта латинская школа (гимназия), обучение в которой было бесплатным, а горожане были достаточно состоятельны, чтобы отправлять детей в школу, а не на заработки. Но реформатор настаивал и на обучении бедных, но способных детей: «Если отец ребенка беден, то нужно помочь церковными средствами. Это обстоятельство богачам следовало бы учитывать в своих завещаниях, как сделали те, которые учредили несколько стипендий» 24 .

То есть, «Проповедь о том, что надо посылать детей в школу» представляет собой действительно своего рода теоретическое осмысление сложившейся в германских землях (прежде всего, Саксонии) за первое постреформационное десятилетие определенной (причем, весьма неутешительной) образовательной практики. И в этом смысле назидательный тон, выбранный Лютером для данного произведения, объясним и оправдан. Кроме того, автор аргументирует свои мысли многочисленными ссылками на Священное Писание, что отличает не только сочинения Лютера, но и жанр проповеди как таковой.

\footnotetext{
${ }^{21}$ Ibidem, c. 140.

22 Ibidem, c. 126.

23 Ibidem, c. 120-121.

24 Ibidem, c. 133.
} 
Таким образом, для Лютера и реформаторов «первой волны» преобразования в области просвещения и организация школ были необходимы в силу не только их понимания сущности спасения, но и как своего рода реализация их реформационной программы через образовательные институты. И проповедь выступила в этом проекте, как основным проводником реформ, так и ведущей формой лютеровского послания следующим поколениям.

\section{Литература}

Lutero M., Il Piccolo Catechismo, a cura di F. Ferrario, Torino 2004.

Melanchton Ph., Unterricht der Visitatorn an die Pfarrherrn im Kurfürstenthum zu Sachssen, Nürnberg 1528.

Ефремова Т., Толковый словарь, Москва 2000.

Йегер В., Раннее христианство и греческая пайдейя, пер. с англ. и вступит. стат. О Алиевой, Москва 2014.

Колб Р., Небольшая, но замечательная книга, www.ihtik.lib.ru/ 2013.05_ihtik_relig/.

Корзо М., Украинская и белорусская катехетическая традиция конца XVI-XVIII вв.: становление, эволюция u проблема заимствований, Москва 2007.

Лурье 3., Полякова М., Брауншвейаский церковный устав Иоганна Бугенхагена о реформе образования, «Proslogion: проблемы социальной истории и культуры средних веков и раннего нового времени» 2018, № 2(4), с. 189-216.

Лютер М., Краткий катехизис, Минск 1996.

Лютер М., Проповедь о том, что нужно посылать детей в школу, пер. О. Курило, [в:] Мартин Лютер - реформатор, проповедник, педагог, Москва 1996, с. 118-154.

Словарь русского языка, Москва 1999.

Толковый словарь русского языка, Москва 1935-1940.

Учитель и ученик: становление интерсубъектных отношений в истории педагогики Востока и Запада (цивилизации Древности и Средневековъя), ред. Н. Баранниковая, В. Безрогов, Москва 2013.

Формирование картины мира в катехизисах Мартина Лютера, [в:] Школьные пособия раннего нового времени: от Часослова $\kappa$ Orbis sensualium pictus, ред. К. Левинсон, Ю. Куровская, В. Безрогов, Москва 2017, с. 114-137.

Чудинов А., Словарь иностранных слов, вошедших в состав русского языка, Санкт-Петербург 1910. 


\section{References}

Lutero M., Il Piccolo Catechismo, a cura di F. Ferrario, Torino 2004.

Melanchton Ph., Unterricht der Visitatorn an die Pfarrherrn im Kurfürstenthum zu Sachssen, Nürnberg 1528.

Yefremova T., Tolkovyy slovar', Moscow 2000.

Jaeger W., Ranneye khristianstvo i grecheskaya paydeyya, per. s angl. ivstupit. stat. O Aliyevoy, Moscow 2014.

Kolb R., Nebol'shaya, no zamechatel'naya kniga, www.ihtik.lib.ru/2013.05 ihtik_relig/.

Korzo M., Ukrainskaya i belorusskaya katekheticheskaya traditsiya kontsa XVI-XVIII vv.: stanovleniye, evolyutsiya i problema zaimstvovaniy, Moscow 2007.

Lur'ye Z., Poliakova M., Braunshveygskiy tserkovnyy ustav Ioganna Bugenkhagena o reforme obrazovaniya, «Proslogion: problemy sotsial'noy istorii i kul'tury srednikh vekov i rannego novogo vremeni» 2018, № 2(4), s. 189-216.

Luther M., Kratkiy katekhizis, Minsk 1996.

Luther M., Propoved' o tom, chto nuzhno posylat' detey $v$ shkolu, per. O. Kurilo, [v:] Martin Luther - reformator, propovednik, pedagog, Moscow 1996, s. 118-154.

Slovar' russkogo yazyka, Moscow 1999.

Tolkovyy slovar' russkogo yazyka, Moskva 1935-1940.

Uchitel' $i$ uchenik: stanovleniye intersub"yektnykh otnosheniy $v$ istorii pedagogiki Vostoka i Zapada (tsivilizatsii Drevnosti i Srednevekov'ya), red. N. Barannikovaya, V. Bezrogov, Moscow 2013.

Formirovaniye kartiny mira $v$ katekhizisakh Martina Luthera, [v:] Shkol'nyye posobiya rannego novogo vremeni: ot Chasoslova $k$ Orbis sensualium pictus, red. K. Levinson, Yu. Kurovskaya, V. Bezrogov, Moscow 2017, S. 114-137.

Chudinov A., Slovar' inostrannykh slov, voshedshikh $v$ sostav russkogo yazyka, Sankt-Peterburg 1910. 